\title{
EFL Students' Suggestions for Enhancing the Constructive Alignment of the English Studies Program in response to the English Proficiency Outcome at the C1 Level
}

\author{
Le Huu Tri ${ }^{1}$ \\ 'Bachelor, School of Foreign Languages, Can Tho University, Vietnam
}

\begin{abstract}
This study was conducted to investigate English Studies majored-students' understanding of the constructive alignment and their suggestions to enhance the constructive alignment in the program in response to the English proficiency outcome at the Cl level. The study was designed qualitatively, employing structuredquestionnaires and individual semi-structured interviews as collecting data instruments, which were mainly constructed from the Constructive Alignment theory of Biggs (2003). 34 senior students majoring in English Studies at a university in the Mekong Delta of Vietnam participated in the questionnaires. Among those participants, 5 students were recruited based on their perceptions on the theme to do the interviews. The findings indicated the high level of students' understanding on the constructive alignment, and their proposed recommendations towards enhancing the constructive alignment in the program. From the findings, the study suggested some implications to boost the constructive alignment. Finally, at the end of the study, the limitations and the suggestions for further research were also discussed.
\end{abstract}

Keywords - Constructive alignment, English proficiency outcome, students' suggestions, enhancing the constructive alignment

\section{INTRODUCTION}

According to Fullan (2007) the student is one of the important stake-holders including the teacher, the school administrator, the student, the parents and the community, and the district administrator, leading to achieving the accomplishment in educational change at the local level. In addition, the new change in education at the local level will be considered successful if it draws all students to be interested and engaged in their learning rather than to be forced on learning (Fullan, 2007). To get the target of engaging students in their learning, students must be treated as a central factor in the educational system, and other stake-holders are expected to satisfy students' holistic development as well as regard their voice and promote their learning motivations (McCombs, 2001).

In the context of Vietnam, the Ministration of Education and Training (MOET, 2018) has also enforced a law in educational change which emphasized on learners' development including knowledge, skills, and attitude in the perspective of learner-centred base instruction. Stake-holders involving in education, therefore, are supposed to respect students' voice and supply them a quality program which can support students to achieve their intended learning outcomes.

Moreover, to evaluate whether a tertiary program is at the high level of quality or not needs a set of framework for measuring its quality. One of the most common measurement models used by educational administrators in ASEAN countries is the Guide to AUN-QA Assessment at Program Level version 4.0 in 2020 by ASEAN University Network Quality Assurance (known as AUN-QA). In version 4.0, the AUN-QA model for program quality evaluation comprises eight criteria including expected learning outcomes, program structure and content, teaching and learning approach, student assessment, academic staff, student support services, facilities and infrastructure, output and outcome (AUN-QA, 2020). In this sense, the Vietnamese Ministration of Education and Training enacted the Circulars No.4 in 2016 on setting standards for assessing the quality of training programs at higher education levels. In this documentary, 11 criteria for assessing the program's quality were elaborately described with clear guidance. Among those criteria, the third one was about the program structure and content which must be designed logically based on the program's intended learning outcomes 
DOI: $\underline{10.51386 / 25815946 / \mathrm{ijsms}-\mathrm{v} 4 \mathrm{i} 5 \mathrm{p} 110}$

Volume: 4 Issue: 5

September to October 2021

https://www.ijsmsjournal.org

(MOET, 2016a). According to the Circulars No.4/2016, the MOET also offered Documentary No. 1074/ 2016 about general guidance on the use of standards for assessing the program structure and content. It was clearly stated in this documentary that the curriculum should be designed in such a constructive way that teaching and learning approach, and student assessment methods can support to achieve the learning outcomes (MOET, 2016b). In other words, the curriculum in the training program should be in accordance with the Constructive Alignment theory of Biggs (2003).

The issue of evaluating the quality of a training program has been received much of attention from a number of researchers in this field. While Zineldin, Akdag, and Vasicheva (2011) presented a new quality assurance model of student satisfaction on the program quality including quality of object, quality of processes, quality of infrastructure, quality of interaction, and quality of atmosphere, Weerasinghe and Fernando (2018) pointed out the key variables of measuring students' satisfaction such as the quality of the academic staff, university facilities, degree program, administrative staff, university location and university image. Furthermore, Worthen (1990) asserted that a program in which the curriculum was well organized to serve the learners' satisfaction on achieving intended learning outcomes was regarded as the high quality one. Additionally, Biggs (2003b) described elaborately that a curriculum where course objectives, teaching practices, and course evaluation were constructively aligned could be deliberated as a well-designed curriculum. Nevertheless, there is limited research on students' understanding of the constructive alignment in their program and how to enhance the program's constructive alignment from the students' viewpoints.

In another case, in the current integrated world, English language has been served as a tool of global communication, particularly it is employed as a crucial foreign language in the Vietnamese context. Nguyen and Burns (2017) revealed in a study that when becoming a member of numerous international organizations, Vietnamese people are required to use English at least to the comprehensible level, so the demand of learning English is always on the top of concerns. Consequently, the need of designing a training program which is able to satisfy the learners' requirements of using English proficiently has become much more necessary than ever before. Moreover, it is said that English Studies program whose expected learning outcomes also involve the ability of using English at the $\mathrm{C} 1$ level of proficiency is one of the most favourable programs for those who desire to mater in English.

As those mentioned reasons, examining students' understanding of the constructive alignment in the English Studies program which supports them achieve the English proficiency outcome at the C1 level and students' suggestions for fostering the constructive alignment in the program really attracts the researcher to conduct this recent study.

As a response to this dearth of understanding of the topic in the existing literature, the current study examines EFL students' perceptions of the constructive alignment at the tertiary level in the Vietnamese context with two purposes. First, this study explores students' understanding of the constructive alignment in the program. Second, it inspects the students' suggestions for enhancing the constructive alignment in the English Studies program in response to achieving the English proficiency outcome at the $\mathrm{C} 1$ level. In accordance with these aims, the study seeks to answer two following specific questions

(1) What are students' overall understanding of the constructive alignment in the program?

(2) What are students' suggestions for enhancing the constructive alignment in the program which supports them to achieve the English proficiency outcome at the $\mathrm{C} 1$ level?

\section{LITERATURE REVIEW}

\section{A. Constructive alignment: Definition and its roles in supporting the achievement of intended learning outcomes}

The term of constructive alignment was originated from the theory of constructivism which focused on meaning. The fundamental idea of constructive alignment was presented by John Biggs in his text entitled "Teaching for Quality Learning at University" (published in 1999) and was revised in 2003, which is now accepted as an essential theory in Higher Education (Biggs, 2003b). According to Biggs (2003b), constructive alignment comprises two aspects including the 'constructive' aspect and the 'alignment' aspect. The constructive aspect refers to the idea of constructing knowledge by the learners themselves through relevant 
DOI: $\underline{10.51386 / 25815946 / \mathrm{ijsms}-\mathrm{v} 4 \mathrm{i} 5 \mathrm{p} 110}$

Volume: 4 Issue: 5

September to October 2021

https://www.ijsmsjournal.org

meaningful learning activities, but not from teachers' explicit instruction, while the alignment aspect infers the assumption of the teacher's activities to create a learning environment supporting the learning activities in line with achieving the intended learning outcomes (Biggs, 2003b). The key principle is that the teaching methods used and assessment tasks are aligned with the learning activities assumed in the intended outcomes.

In his theory, Biggs (2003a) depicted four sequential steps for designing a constructively aligned curriculum encompassing defining the intended learning outcomes (ILOs), selecting teaching and learning activities (TLAs), assessing students' actual performance, and arriving at a final grade. In detail, Biggs (2003b) described those steps more elaborately that the learning outcomes should be formulated first to decide which learning content and teaching practices are sensible. Next, the assessment tasks should be designed based on intended learning outcomes and learning experiences occurred in the classroom. Through the valid assessment, the curriculum developer or the course designer can check what the learners are able to do and to what extent the learning outcomes are achieved so that he or she can make some necessary interventions. It indicated that all the learning and teaching activities and assessment methods must be designed in such a way of serving to achieve the intended learning outcomes.

According to Biggs (2003b), intended learning outcomes are what the students will be able to do at the end of a training course. As a result, teachers must comprehend clearly the intended learning outcomes (ILOs) in the course and how those ILOs contribute to achieving the students' board goals. Furthermore, the intended learning outcomes should be declared to students at the beginning of the course, by that way students can well understand what they would have achieved by the time of ending the course, and they might have some careful preparation or set their own learning strategies to obtain those intended outcomes.

Once defining the intended learning outcomes, the curriculum developer or the teacher is expected to select the suitable learning contents and materials that can assist to achieve the target outcomes (Biggs, 2003a). Moreover, Fullan (2007) claimed that the learning contents and materials need to be authentic and related to the intended learning outcomes so that learners are able to make their learned knowledge and skills into function. In more detailed, Braun (2005) described several characteristics for perfect language materials which are realistic, informative, illustrative, and up-to-date.

In constructive alignment approach, learners actively construct their knowledge meaningfully through learning activities, and knowledge is not transmitted by teachers' direct instruction (Biggs, 1999). In his book 'Aligning teaching for constructing learning' published in 2003, Biggs (2003a) also stated several principles for appropriate learning activities, including motivational context, interaction with others, and well-structured knowledge base. Accordingly, deep learning is more likely to occur when students have a need or motivation to know something for dealing with challenging but doable tasks designed based on Vygotsky's model of zone of proximal development (Kozulin, 2004). Moreover, it is often easier for students to negociate meaning with others like peer interacting, and peer teaching rather than only lecturing. Additionally, students' prior knowledge and experience play an important role as a bridge that connects the previous knowledge with the new one (Brown, 2007); hence, organizing teaching and learning activities which requires students to take advantages of prior knowledge is highly encouraged.

In choosing the assessment tasks accordance with the constructive alignment theory, Biggs (1996) asserted that when designing assessment tasks, the teacher must judge the extent to which those tasks comprise the target performances of understanding and how well they are suitable with evaluating individual student performances. In addition, according to Biggs and Tang (2011), the assessment is considered as a linking sequence in which selecting assessment methods is at the end of the teaching-learning sequence of events to the teacher, but to the students it is at the beginning. The intended learning outcomes, therefore, should be aligned with the assessment, and the assessment methods as well as grading criteria should be informed to students before assessment occurrence so that students can set their own learning strategies and activities for themselves to achieve the learning outcomes (Biggs \& Tang, 2011).

In light of constructivist views, Berry (2011) and Gallagher (2017) also stated that the aim of assessment is to understand how the learners learnt, what they are able to do, and make some interventions to help them attain the intended learning outcomes; therefore, the assessment methods should reflect the variety of learning outcomes. Then, teachers can use the formative assessment results to understand more about the students' learning progress. And, an assessment is called formative when it is designed to facilitate students' learning 
DOI: $\underline{10.51386 / 25815946 / \mathrm{ijsms}-\mathrm{v} 4 \mathrm{i} 5 \mathrm{p} 110}$

Volume: 4 Issue: 5

September to October 2021

https://www.ijssmsjournal.org

through testing the learners on regular basis to identify their difficulties in constructing knowledge driven to the intended outcomes (Nicol \& Macfarlane-Dick, 2004).

According to Nicol (2004), the teacher would rather offer regular feedback in order to provide a flow of information to students so that they can realize their strengths and weaknesses. In this sense, formative assessment and regular feedback are really vital to serve students' self-regulated learning.

\section{B. English proficiency outcome at the $\mathbf{C 1}$ level in the English Studies program}

In the Vietnamese context, the Prime Minister has enacted Decision No.1984 on Approval for Vietnamese Qualifications Framework since 2016 so as to set expected standards for eight levels in the Vietnamese educational system. The expected standards including knowledge, skills, and autonomy and responsibility were carefully specified for each of the level. In particular, learners belonging to Bachelor level (level 6) are expected to have solid practical knowledge, in-depth knowledge of a training discipline, basic knowledge of social sciences, politics and laws. In terms of skills, the bachelor graduates will be able to own cognitive skills related to criticism, analysis and synthesis; professional skills, and effective communication skills. For the level of autonomy and responsibility, those learners at Bachelor level will enable to work independently or in group under inconsistent working-conditions, take personal responsibility and group responsibility when graduating (Minister, 2016).

Accordantly, the administrators of universities can formulate intended learning outcomes for their training programs under the guidance of mentioned Decision No.1984 of the Prime Minister. Specially, for English Studies program, most of the administrators of universities in Vietnam share a quite common set of intended learning outcomes divided into three sections including knowledge, skills, and the level of autonomy and responsibility. Among intended learning outcomes in the English Studies program, the outcome of achieving English proficiency at the $\mathrm{C} 1$ level is considered as one of the most noticeable features in the program.

According to the Common European Framework of Reference for Languages (CEFR), those learners at the $\mathrm{C} 1$ level known as proficient users can understand a variety of longer texts, and recognize implicit meaning; express themselves fluently and spontaneously without much obvious searching for expressions; use language effectively for social, academic and professional purposes; produce precise texts on complex subjects, showing the controlled use of organizational patterns, connectors and cohesive devices (Council, 2011). In light of the CEFR framework, the intended learning outcome of English proficiency at the C1 level in English Studies program was clearly depicted that by the end of the program, students will be able to understand television programs and films in English without too much effort; understand specialized articles and longer technical instructions; express themselves fluently and spontaneously for social and professional purposes without much obvious searching for expressions; precisely present descriptions of complex subjects; and write about complex subjects in well-structured texts (Trinh, 2018). As mentioned above, there are a bunch of intended learning outcomes in the English Studies program, but in the scope of this study, the researcher just paid much attention on the English proficiency outcome at the $\mathrm{C} 1$ level because it is regarded as the distinguished feature of English Studies majored-students compared with non-English majored-ones.

\section{Related Studies}

With regard to empirical research that focuses on the constructive alignment, although in general, a limited number of studies are available, findings from these studies establish crucial bases for understanding the students' perceptions of the constructive alignment in various contexts. For instance, in a study of $30 \mathrm{EFL}$ students in Bahrain, Jaiswal (2019) found that the constructive alignment of intended learning outcomes, teaching and learning activities, and assessment tasks, using the objective model of Bloom's taxonomy and Biggs' SOLO taxonomy had a statistically positive impact on learners' academic achievement in enhancing their proficiency levels. Furthermore, the researcher in this case study also pointed out four factors to facilitate the teaching and learning process such as establishing positive learning environment, linking academic content to real life situations, selecting appropriate teaching learning activities and developing attainable learning outcomes. In another study conducted by Jani, Latif, Talib, and Is (2020) with Malaysian students, it was found that most of the participants' approval of constructive alignment practices in teaching activities was at the "high practice". Moreover, the study suggested that intended learning outcomes should be delivered to students and showed that the administered assessment was applicable and objective with rubric for required assignments. In the research of exploring how different elements of constructive alignment influence the learning approach 
DOI: $\underline{10.51386 / 25815946 / \mathrm{ijsms}-\mathrm{v} 4 \mathrm{i} 5 \mathrm{p} 110}$

Volume: 4 Issue: 5

September to October 2021

https://www.ijsmsjournal.org

students adopt, Hailikari, Virtanen, Vesalainen, and Postareff (2021) indicated that organizing teaching and learning activities played a vital role in orienting students' learning approach towards the intended learning outcomes. While active teaching and learning activities which provided enough challenges, required active involvement, and encouraged peer support had a big role driving students to deep learning, traditional courses with only lectures and final examinations, and without students' active engagement made students adopt the unreflective or mixed learning approach.

In another case in Vietnam, Nguyen \& Laws (2019) revealed the findings that there was a significant change in teachers' perceptions from blaming for being limited power in curriculum construction to being aware of the role of their voices in constructing the curriculum. In addition, this study also indicated the limitation that students" agency in co-constructing the curriculum and the "being" of curriculum, which should have been taken into account, were neglected. In addition, a case study of Nguyen (2020), conducted at a university in Ho Chi Minh city to examine how constructive alignment was practiced in an AUN-designed course for a Speaking class of English majors with the participation of 30 students and their lecturers pointed out that although the participants accepted the positive effects of constructive alignment in triggering students' motivation towards getting the learning outcomes and making reliable criteria for assessing students, it was partly founded in the classroom. Research that directly investigates the students' understanding of the constructive alignment and their suggestions for boosting the constructive alignment in the English Studies program in this context, however, appears to be neglected.

\section{RESEARCH METHODOLOGY}

\section{A. Research method}

To explore the students' understanding of the constructive alignment and their suggestions for enhancing the constructive alignment in the English Studies program in response to helping them achieve the English proficiency outcome at the $\mathrm{C} 1$ level in a particular context of a Vietnamese university, the current study employed a qualitative research design with data collected via questionnaires and individual semi-structured interviews. This qualitative design was utilized and viewed as most suitable for its power in allowing the researchers to probe into the students' in-depth understanding of the theme and their opinions on how to foster the constructive alignment in the program (Corbin \& Strass, 2008). The questionnaires in this study were designed to explore how students understood about the constructive alignment in the program, followed by semi-structured interviews to investigate what students suggested to enhance the constructive alignment in the program. These interviews help the researcher gain a better understanding of the topic under the investigation and interpretation of a phenomenon (Cohen \& Morrison, 2007).

\section{B. Participants}

Participants were the senior students whose major was English Studies at a well-known university in the Mekong Delta in Vietnam. They had different demographic information and experiences. The participants were invited to do the questionnaire via Google Forms for investigating their overall understanding of the constructive alignment in the program. 34 EFL students whose major is English Studies participated in completing the questionnaire. Table 1 below summarizes the students' demographic information.

\section{TABLE 1}

SUMMARY OF THE PARTICIPANTS' DEMOGRAPHIC INFORMATION

\begin{tabular}{cccc}
\hline Participants' information & Variables & Number & Percentage \\
\hline \multirow{2}{*}{ Gender } & Male & 14 & $41.2 \%$ \\
& Female & 20 & $58.8 \%$ \\
& Year 3 & 11 & $32.4 \%$ \\
Years & Year 4 & 23 & $67.6 \%$ \\
& & & \\
\hline
\end{tabular}


DOI: $\underline{10.51386 / 25815946 / \mathrm{ijsms}-\mathrm{v} 4 \mathrm{i} 5 \mathrm{p} 110}$

Volume: 4 Issue: 5

September to October 2021

https://www.ijsmsjournal.org

Table 1 showed the participants' demographic information including genders (14 male students and 20 female ones), and the number of learning experience years in their major (11 third-year students and 23 forthyear ones).

Next, the semi-structured interviews were conducted with the participation of 5 English Studies majoredstudents, named as S1, S2, S3, S4, and S5, who were recruited to join in the interviews based on their understanding of the constructive alignment in the program answered in the questionnaires. Table 2 below showed the information of these students.

TABLE 2

INFORMATION OF PARTICIPANTS FOR INDIVIDUAL SEMI-STRUCTURED INTERVIEWS

\begin{tabular}{cccccc}
\hline Information & S1 & S2 & S3 & S4 & S5 \\
\hline Gender & female & male & female & male & 3 \\
Years & 4 & 4 & 4 & 3 \\
\hline
\end{tabular}

As observed in the table, 3 female and 2 male students, who were in the 3 rd and 4 th year experiencing in English Studies program, involved in the interviews. Because of differences in demographic information and the number of learning years in the program, their provided data would help the researcher have diverse perspectives from different triangulations for the research topic.

\section{Instruments}

\section{1) Questionnaires}

One of the advantages of using questionnaire to collect data indicated by Edwards (1991) is giving the participants a considerable amount of time to consider their thoughts on the issues. The questionnaire consisted of a series of questions or statements that allow participants to respond and write down their thoughts (Brown, 2001). Gillham (2008) also indicated that the researcher can collect various responses of the participants on a large population with the questionnaire.

As earlier mentioned, questionnaires were employed in this study to explore the students' understanding of the constructive alignment in the program. Accordingly, a questionnaire was designed with 5 question items. Questions 1 and 2 required the students to provide their personal information including gender and years of experience in learning at the university, while questions 3 and 4 asked them to give their name and phone number for later contact. Question 5 focused on exploring their understanding of the constructive alignment of the program.

Thirty-four questionnaires written in Vietnamese were conducted with individual students with each questionnaire lasting from 10 to 15 minutes. The students were allowed to use either English or Vietnamese to answer the questionnaires as long as they felt most convenient and confident to share the most in-depth information as they could. All of the questionnaires were then transcribed and translated into English and cocoded by the researcher and the researchers' classmates.

\section{2) Semi-structured interviews}

Gray (2004) claimed that interviewing is a serviceable tool for collecting data from individuals because it can gather the information in-depth through the communication of the researcher and the participants. Despite the convenience of questionnaire in collecting quantitative data, it still has some limitations in offering participants an opportunity to express more ideas in detail. Consequently, using interviews is a good alternative option to improve those weaknesses of using the questionnaires (Macaro, 2001). As a result, in this study, the researcher invited five participants majoring in English Studies at a university in Mekong Delta among those participating in the questionnaires to join in individual semi-structured interviews to confirm the questionnaire 
DOI: $\underline{10.51386 / 25815946 / \mathrm{ijsms}-\mathrm{v} 4 \mathrm{i} 5 \mathrm{p} 110}$

Volume: 4 Issue: 5

September to October 2021

https://www.ijsmsjournal.org

results and attain more insights on the students' suggestions for enhancing the constructive alignment of their program to help them achieve the English proficiency outcome at the $\mathrm{C} 1$ level. The interview, which lasted around fifteen minutes depending on the respondents' answers, would be conducted after administrating questionnaires. The responses were recorded, transcribed, and translated into an English version to serve the interview data analysis.

The reason for using semi-structured interviews is that ambiguous responses are able to be explained clearly by the participants in the semi-structured interview, which enables the researcher to explore deeper into the given phenomenon Mackey and Gass (2005). In addition, a semi-structured is better than a restrictive structured interview which is too restrictive to obtain in-depth information and a completely unstructured interview which neglects direction and focus (Mackey \& Gass, 2005).

The interviewed participants were asked how to enhance the constructive alignment of the English Studies program in light of helping them achieve the English proficiency outcome at the $\mathrm{C} 1$ level from their perspectives. Consequently, the interview included four main questions related to students' suggestions for fostering the constructive alignment in terms of the intended learning outcome, the learning contents; the teaching methods; and the assessment methods. For each main question, the researcher employed some subquestions when necessary to elicit participants' answers as well as to go deep into discussion for more insights.

To assure the validity of the collected data, the interview questions were translated into Vietnamese to assist the participants deeply understand the meaning of the interview questions and easily express their opinions relevant to them. The interview questions were also checked with the researcher classmates, and interview pilots were conducted prior to the actual interviews. The translation of respondents' answers was checked with the external readers to ensure the validity of the data. Moreover, the researcher also asked another researcher classmates to translate the scripts to compare with the official transcript version. The result showed that they were nearly $95 \%$ the same. Hence, it could be said that the official transcript version was reliable enough to report later.

\section{FINDINGS AND DISCUSSION}

In this section, the main findings from the study would be reported in accordance with the two research questions around which the study was central. Qualitative data collected from the questionnaire were analyzed first to gain students' in-depth understanding of the constructive alignment in the program. Moreover, this section also indicates several students' suggestions to enhance the constructive alignment of the English Studies program which supports them to achieve the English proficiency outcome at the $\mathrm{C} 1$ level from their perspectives.

\section{A. Students' understanding of the constructive alignment in the program}

The first aspect which the current study aimed to explore was the students' understanding of the constructive alignment in the English Studies program. Evidence from the students' responses in the questionnaires clearly revealed that all the participants were fully aware of the term "constructive alignment" and its crucial role in supporting them to achieve the intended learning outcome.

Student 5 , for instance, stated that "I think the constructive alignment is a close connection of the course objectives and learning activities as well as assessment tasks", while Student 2 confirmed that in the curriculum development, "the constructive alignment is one of the key components of a well-organized curriculum". Similarly, Students 1 and 3 reconfirmed that "learning contents and test contents must be aligned with the intended learning outcomes in light of constructive alignment theory". Those assumptions of the participants are in consistent with the constructive alignment theory of Biggs (2003) in which intended learning outcomes, teaching and learning activities, and assessment methods are logical structured so that learners cannot escape from what they are going to attain. Likewise, Student 4 highlighted the important role of constructive alignment in response to the achievement of intended learning outcomes, saying "in my opinion, when teachers having in mind the sense of applying constructive alignment theory in teaching practice, they will initially formulate intended learning outcomes, from which appropriate learning contents and effective teaching methods as well as assessment tasks can be drawn out". This viewpoint is in line with the principle of designing a constructively aligned course of Biggs and Tang (2011) that stated assessment tasks must be aligned and reflective the intended 
DOI: $\underline{10.51386 / 25815946 / \mathrm{ijsms}-\mathrm{v} 4 \mathrm{i} 5 \mathrm{p} 110}$

Volume: 4 Issue: 5

September to October 2021

https://www.ijsmsjournal.org

outcomes. From those participants' responses, it could be seen that most of the students appeared to comprehend the idea of constructive alignment in curriculum development which served the accomplishment of the intended learning outcomes. For English Studies majored-students' overall understanding of the constructive alignment in the program, according to the qualitative analysis, this finding of the study indicated that English Studies majored-students were highly comprehensible to the constructive alignment in the program towards helping them achieve the C1 level of English proficiency. This result was consistent with that of Jaiswal (2019), which showed a high level of positive impact of the constructive alignment using the objective model of Biggs' taxonomy on learners' academic achievement in boosting their proficiency levels.

\section{B. Students' suggestions for enhancing the constructive alignment in the program}

The second major pedagogical aspect that this study was designed to explore was the students' suggestions for boosting the constructive alignment in the English Studies program which supports students to achieve the English proficiency outcome at the $\mathrm{C} 1$ level. This sections would reported students' suggestions in detail aspects of the constructive alignment needed improving.

In terms of the program outcomes, the declaration of the English proficiency outcome at the $\mathrm{C} 1$ level and an elaborative guideline for obtaining that target should be clearly informed at the start of the course. To this point, student 2 suggested that,

"Well, I thought that lecturers should declare clearly the objectives of the course, especially the English proficiency outcome at the C1 level. Although teachers had announced the objectives to student, they were quite general. Therefore, I assumed that they should pay more attention to the English proficiency outcome at the C1 level and share some strategies on how to get it." (Student 2, block 4)

It could be seen from Student 2's remark that the guidance of English proficiency outcome at the C1 level was not very effective, so it needed to be more formative and detailed.

For the learning contents, it should be closely linked the knowledge of prior courses and later ones in light of supporting learners to gain $\mathrm{C} 1$ gradually. In this case, Students 3 and 5 shared the same idea that,

"... I thought that it would be ok if we edited the learning content in such a way that courses in the program had a great linking to one another. From my experience, I saw it quite loose at my time. "(Student 3, block 6)

In the same case, Student 5 said that,

"Well, let me see... I assumed that some courses should be re-arranged in a more logical way in which prior courses could contribute to the success of later ones, leading to achieving the English proficiency outcome at the C1 level at the end" (Student 5, block 6)

According to students' comments on the constructive alignment, it could be inferred some learning contents in the program would rather be re-ordered in a more linking sequence to ensure the achievement of intended outcomes.

Regarding teaching methods, some teachers were suggested to teach in a more intensive way with a clear main point for a unit. Particularly, Student 1 presented the idea that,

"My suggestion was that several lecturers needed to modify their teaching methods suitable for the course. I meant it was necessary to help students gain key points by the end of the course. In other words, lecturers should teach more intensively."'(Student 1, block 8)

From students' perspectives, it was obvious that the teaching methods of some teachers were not really effective in assisting learners to attain the main points of course dominated in the program outcomes. Teaching methods, hence, are expected to be modified in such a positive way that can engage students in learning activities.

In terms of testing, lecturers should often offer students stimulating proficiency tests related to English 
DOI: $\underline{10.51386 / 25815946 / \mathrm{ijsms}-\mathrm{v} 4 \mathrm{i} 5 \mathrm{p} 110}$

Volume: 4 Issue: 5

September to October 2021

https://www.ijsmsjournal.org

proficiency at the C1 level like IELTS, TOEFL, or VSTEP to make them familiar with the format of those tests. For instance, Student 3 reported that:

“...In my opinion, it was likely to lack complete mock tests driving to English proficiency standard, so I think it would be better if we were exposed to those tests frequently during the program so that we could be familiar with them later on"(Student 3, block 4)

From the result of those tests, students could identify their current knowledge to set their own plan and strategies towards the target of English proficiency at the C1 level.

In terms of learners themselves, they were expected to be more responsible for their own learning. In detail, student 4 said,

"I thought that students should positively show their expectations towards the course. It was because if students didn't express clearly their wants, teachers would not be able to know what students needed to improve. Therefore, students should be more positive."(Student 4, block 6)

Based on Student 4' suggestion, it could be stated that the role of learners themselves in achieving the intended learning outcomes is extremely important because they are able to obtain their learning goals only when they clearly determine their objectives and take responsibility for their own learning.

In terms of another stake-holders, students suggested "the administrators of school or department should come to class occasionally to observe what actually happened in class" (Student 4, block 8). And from those observations, some valuable recommendations to make the teaching practice more effective could be drawn from.

In this study, students were provided an opportunity to raise their "voices" on how to enhance the constructive alignment in the program. In other words, students' agency in co-constructing a proper constructive curriculum was taken into account. Those students' suggestions in this study had been mentioned as a gap that needed fulfilling in the study of Nguyen \& Laws (2019).

\section{IMPLICATIONS AND CONCLUSION}

This study was aimed to examine EFL students' overall understanding of the constructive alignment and how to enhance the constructive alignment in the English Studies program in response to helping them achieve English proficiency outcome at the $\mathrm{C} 1$ level. A prestigious university in the Mekong Delta was selected as the research site because of its reputation in educational quality in the region. For the research instruments, questionnaires and interviews were employed to collect qualitative data. On the foundation of the research questions, the data analysis emerged some main findings as below.

The research question 1 was answered by the findings of qualitative analysis from the questionnaire. The findings showed that the students' overall understanding of the constructive alignment in the program was high irrespective of different demographic information.

Apart from the findings of students' understanding of the constructive alignment, the study also answered research question 2 by collecting a wide range of students' valuable suggestions for enhancing the constructive alignment towards the English proficiency outcome at the $\mathrm{C} 1$ level from qualitative results which could be summarized as the following.

For intended learning outcomes, the declaration of achieving the $\mathrm{C} 1$ outcome should be taken at the start of the course, and elaborative guideline and tips for achieving that outcome should be also supplied to students. Turning to the learning content, there should be a strong connection from knowledge in the prior courses to the later ones. In other words, English courses should be ordered consistently in response to the English proficiency outcome at the $\mathrm{C} 1$ level. In terms of teaching and learning activities, flexible teaching techniques suitable with students' current knowledge and interest should be employed. Moreover, cooperative activities oriented to the proficiency outcome like pair work or group work that required much communicative interaction were highly recommended. For some teachers, they were recommended to teach more intensively with clear key points for 
DOI: $\underline{10.51386 / 25815946 / \mathrm{ijsms}-\mathrm{v} 4 \mathrm{i} 5 \mathrm{p} 110}$

Volume: 4 Issue: 5

September to October 2021

https://www.ijsmsjournal.org

each unit. In terms of testing and assessment, students had a desire of being familiar with proficiency tests like IELTS, TOEFL, or VSTEP at the C1 level of English proficiency. For stake-holders, classroom observations should be carried out occasionally by the responsible department administrators to see what actually happened in class and have in-time interventions when necessary for bettering the teaching and learning process. Regarding learner factor, they had better be more responsible for their own learning and take their study seriously.

The study presented positive results in students' understanding of the constructive alignment in the program in light of achieving the intended learning outcome at the $\mathrm{C} 1$ level of English proficiency. Therefore, it should be kept developing as before. Moreover, the administrators of the school and department should monitor the practice of constructive alignment more than usual by classroom observations or perceiving students' responses to see how constructive alignment are actually implementing in the program and have in-time intervention if necessary. In addition, when designing a constructive alignment curriculum, the administrators are expected to concern students' voice in order to design an appropriate curriculum aligning with the intended learning outcomes.

Although many teachers had effective teaching methods and created active teaching learning activities for students to construct knowledge by themselves, some others were not very successful in their teaching practice. Hence, in terms of teachers, some of them are supposed to modify their teaching practice by staying focus on the lesson outcomes, organizing more cooperative teaching and learning activities that require students' involvement in particular. Moreover, lecturers ought to assert the intended learning outcome of the course at the beginning and share some useful strategies on how to achieve that target to all students.

In addition, regarding learner factor, students are required to take their study more seriously and positively, show their needs as well as raise their voice in necessary situations. By that way, the teachers and administrators can see their learning needs so that they can design a suitable curriculum and effective teaching activities to serve for achieving those desirable targets.

Finally, for the scientific researchers, who are intended to conduct the study related to the constructive alignment in EFL program, in particular students' perceptions of the constructive alignment towards proficiency outcome, this study found several appealing results in terms of students' understanding with the theme and their suggestions to boost the constructive alignment in the program. Therefore, those findings in this study can have contributed to the review of literature of the field in further studies.

However, limitations in this study are unavoidable, regardless of many efforts made by the researcher to attain the research aims. In terms of sample population, the study was conducted on a small population of participants in a university of Mekong Delta. Therefore, the results cannot be generalized to all English Studies majored-students in general. Moreover, the findings of the study were based on the self-reported information from the students. There were not any observations or fieldtrips made to check the self-reported data; consequently, particular limitations regarding the reliability in the study could not be avoided.

Based on the limitations mentioned above, some suggestions have been drawn out for further studies. First, further research in the field should be conducted with more participants on the larger population in order to generate the findings on a large scale. Secondly, it is suggested that further research should be conducted on teachers' perceptions of the constructive alignment of the program in response to English proficiency outcome in order to compare with those of students.

\section{ABOUT THE AUTHOR}

Le Huu Tri is an English teacher at a high school in Dong Thap province, Vietnam. He completed a Bachelor's degree in English Education in 2018. He is currently an MA student at Can Tho University. He is fond of researching curriculum development, constructive alignment in the program and professional development.

\section{REFERENCES}

[1] AUN-QA (2020). Guide to AUN-QA Assessment at Programme Level version 4.0 (2020), Bangkok: Thailand. 
DOI: $\underline{10.51386 / 25815946 / \mathrm{ijsms}-\mathrm{v} 4 \mathrm{i} 5 \mathrm{p} 110}$

Volume: 4 Issue: 5

September to October 2021

https://www.ijsmsjournal.org

[2] Berry, R. (2011). Assessment reforms around the world Assessment reform in education (pp. 89-102): Springer.

[3] Biggs, J. (1999). Teaching for quality learning at university. The UK: Buckingham: SRHE/OU Press.

[4] Biggs, J. (2003a). Aligning teaching for constructing learning. Hong Kong: the Higher Education Academy.

[5] Biggs, J. (2003b). Teaching for quality learning at university (2nd edition). Buckingham: Open University Press/Society for Research into Higher Education.

[6] Biggs, J. (1993). From theory to practice: A cognitive systems approach. Higher education research and development, 12(1), 73-85.

[7] Biggs, J. (1996). Enhancing teaching through constructive alignment. Higher education, 32(3), 347-364.

[8] Biggs, J., \& Tang, C. (2011). Teaching for quality learning at university: McGraw-hill education (UK).

[9] Braun, S. (2005). From pedagogically relevant corpora to authentic language learning contents. ReCALL, 17(1), 47-64.

[10] Brown, D. J. (2001). Using surveys in language program. NY: Cambrige University Press.

[11] Brown, H. D. (2007). Principles of Language Learning and Teaching (5th ed.). New York: PEARSON Longman.

[12] Corbin, J., \& Strauss, A. L. (2008). Basics of Qualitative Research (3rd Edition). Thousand Oaks: SAGE Publications, Inc.

[13] Cohen, M. L., \& Morrison, K. (2007). Research Methods in Education (6th Ed). New York: Taylor \& Francis e - Library publishers

[14] Council, o. (2011). Common European Framework of Reference for Languages: Learning, teaching, assessment. Cambridge: Cambridge University Press.

[15] Edwards, J. (1991). Evaluation in adult and further education: a practical handbook for teachers and organizers: Workers' Edu cational Association.

[16] Fullan, M. (2007). The New Meaning of Educational Change 4th. New York: Teachers College Press.

[17] Gallagher, G. (2017). Aligning for learning: Including feedback in the Constructive Alignment model. All Ireland Journal of Higher Education, 9 (1).

[18] Gillham, B. (2008). Developing a questionnaire. London: A\&C Black.

[19] Gray, D. (2004). Doing research in the real world: Qualitative and quantitative approaches. Thousand Oaks: Sage Publications Inc.

[20] Hailikari, T., Virtanen, V., Vesalainen, M., \& Postareff, L. (2021). Student perspectives on how different elements of constructive alignment support active learning. Active Learning in Higher Education, 1469787421989160.

[21] Jaiswal, P. (2019). Using Constructive Alignment to Foster Teaching Learning Processes. English Language Teaching, 12(6), 10-23.

[22] Jani, M. D. B. M., Latif, A. B. A., Talib, R. B., \& Is, N. B. M. (2020). The implementation of constructive alignment at the teachers education institute using rasch analysis. Journal of Critical Reviews, 7(11), 659-665.

[23] Kozulin, A. (2004). Vygotsky's theory in the classroom: Introduction. European Journal of Psychology of Education, 3-7.

[24] Macaro, E. (2001). Learning strategies in foreign and second language classrooms: The role of learner strategies: A\&C Black.

[25] Mackey, A., \& Gass, S. M. (2005). Second language research: Methodology and design. Mahwah: NJ Lawrence Erlbaum Associates.

[26] McCombs, B. L. (2001). What do we know about learners and learning? The learner centered framework: Bringing the educational system into balance. Educational Horizons, 79, 182-193.

[27] Minister, T. P. (2016). Decision on Approval for Vietnamese Qualifications Framework. Decision No.1982/The Prime Minister.

[28] MOET. (2016a). The Circular promulgates regulations on standards for assessing the quality of training programs at high er education levels. 04/2016/TT-BGDĐT.

[29] MOET. (2016b). General guidance on the use of standards for assessing the quality of training programs at higher education levels. Documentary No. 1074/KTKĐCLGD-KĐĐH/ BGDĐT.

[30] MOET. (2018). General Education Program - Master Program. Circulars No. 32/2018/TT-BGDĐT.

[31] Nguyen, H. T. M., \& Burns, A. (2017). Teacher language proficiency and reform of English language education in Vietnam, 20082020. Phnom Penh, 19. 


\section{DOI: $\underline{10.51386 / 25815946 / \mathrm{ijsms}-\mathrm{v} 4 \mathrm{i} 5 \mathrm{p} 110}$}

Volume: 4 Issue: 5

September to October 2021

https://www.ijsmsjournal.org

[32] Nguyen, T. M. (2020). Constructive alignment in teaching english at tertiary level: an insight into an aun-designed course. Paper presented at the Proceedings of the 8th OpenTESOL International Conference 2020, Ho Chi Minh City Open University.

[33] Nguyen, T. V. S., \& Laws, K. (2019). Changes in higher education teachers' perceptions of curriculum. Journal of Applied Research in Higher Education.

[34] Nicol, D., \& Macfarlane-Dick, D. (2004). Rethinking formative assessment in HE: a theoretical model and seven principles of good feedback practice. C. Juwah, D. Macfarlane-Dick, B. Matthew, D. Nicol, D. \& Smith, B.(2004) Enhancing student learning though effective formative feedback, York, The Higher Education Academy.

[35] Trinh, Q. L. (2018). Bachelor's Degree Program in English Studies. Vietnam: CanTho University.

[36] Weerasinghe, I. M. S., \& Fernando, R. L. S. (2018). Critical factors affecting students' satisfaction with higher education in Sri Lanka. Quality Assurance in Education, 26(1), 115-130. doi: https:// doi.org/10.1108/QAE-04-2017-0014

[37] Worthen, B. R. (1990). Program Evaluation. In H. Walberg \& G. Haertel (Eds.), The international encyclopedia of educational evaluation. Toronto: ON: Pergammon Press.

[38] Zineldin, M., Akdag, H. C., \& Vasicheva, V. (2011). Assessing quality in higher education: new criteria for evaluating students' satisfaction. Quality in Higher Education, 17(2), 231-243. 